Revista Complutense de Educación

ISSNe: 1988-2793

https://dx.doi.org/10.5209/rced.63192

\title{
Indicadores Comentados sobre el Estado del Sistema Educativo Español 2018
}

Autores: Ma Auxiliadora Ruiz Rosillo, Miguel Ángel Sancho Gargallo y Mercedes de Esteban Villar

Editorial: Centro de Estudios Ramón Areces

Año de publicación: 2018

$N^{o}$ de páginas: 192

Este libro es un trabajo de actualización de la situación y evolución del sistema educativo español referido al año 2018, con una intención comparativa y elaborado a partir de fuentes estadísticas e informes nacionales e internacionales sobre educación.

Como en anteriores trabajos de estos autores auspiciados por las fundaciones "Ramón Areces" y "Europea Sociedad y Educación" el objetivo del libro se centra en analizar breve y descriptivamente aspectos que permiten entender y estudiar las características más destacadas de nuestro sistema educativo para propiciar el debate público a la luz de estos datos expuestos.

El equipo de comentaristas expertos en educación que ha colaborado en esta ocasión ha sido compuesto por Juan Carlos Rodríguez, Toni Mora, Soledad Iglesias Jiménez, José García Montalvo, Julio Carabaña, Jennifer Graves, Miguel Ángel Sancho Gargallo, Mauro Mediavilla, Elena Martín, Mariano Fernández Enguita, Petra María Pérez Alonso-Geta, Francesca Borgonovi y Jorge Calero.

En la primera parte, La educación en España, se amplían las informaciones sobre la población escolar, nivel de educación poblacional, y la distribución de tasas de escolarización por enseñanzas, incluyendo en muchos casos datos de su evolución hasta 2018.

En el segundo bloque, Recursos educativos, se recogen el gasto público por alumno y por actividad educativa, y su relación con el PIB junto con datos sobre las becas y ayudas al estudio; datos relativos al profesorado, la ratio y tamaño del aula; el uso de internet y ordenadores en las actividades de enseñanza y aprendizaje; todo ello siguiendo el esquema de anteriores informes de estos autores (Ruiz Rosillo et al., 2017; Ruiz Espejo, 2018).

En el tercer apartado de Resultados educativos, se aportan datos de evolución de España con respecto a los objetivos europeos para los sistemas de educación y formación, y se incluyen por primera vez en este estudio información sobre indicadores de competencia financiera y sobre resolución colaborativa de problemas, a partir de PISA 2015 y PIRLS 2016. El entorno, clima escolar, destrezas no cognitivas en los datos de rendimiento se incluyen en esta sección por primera vez.

En la sección de Educación y empleo se incluyen datos relativos a la participación en actividades de aprendizaje permanente; iniciativas nacionales desarrolladas para la promoción del empleo y la formación en los jóvenes, como el Programa de 
Garantía Juvenil y los contratos de formación y aprendizaje. También se describen datos del nivel educativo y situación laboral, comentados por el economista y profesor Jorge Calero.

El libro incorpora las referencias bibliográficas consultadas para la elaboración del mismo; fundamentalmente provienen de la Comisión Europea, del Ministerio de Educación, Cultura y Deporte, de la OCDE, y del Boletín Oficial del Estado. Un glosario de términos y la clasificación internacional de la educación (CINE) completan la exposición del material. En la presente obra se han realizado 86 gráficos y 17 tablas, muchos de ellos en color. Una magnífica presentación para el propósito planteado con su elaboración.

\title{
Referencias bibliográficas
}

Ruiz Espejo, M. (2018). Reseña de "Indicadores Comentados sobre el Sistema Educativo Español 2017". Revista Complutense de Educación, 29 (3), 939-940.

Ruiz Rosillo, M. A., Sancho Gargallo, M. Á. y de Esteban Villar, M. (2017). Indicadores Comentados sobre el Sistema Educativo Español 2017. Madrid: Editorial Centro de Estudios Ramón Areces.

\author{
Mariano Ruiz Espejo \\ ruizesp@gmail.com
}

Universidad Católica San Antonio de Murcia 